\title{
Una burla de Feliciano de Silva sobre el hombre salvaje en la Tercera parte del Florisel de Niquea ${ }^{1}$
}

\author{
Feliciano de Silva's Joke About the Wild Man Played \\ in the Third Part of Florisel de Niquea
}

Alberto del Río Nogueras

(Universidad de Zaragoza)

\section{RESUMEN}

Estudio de un episodio de la Tercera parte del Florisel de Niquea de Feliciano de Silva (capítulo 77) en el que se combinan una burla (recaudo falso) al legendario hombre salvaje, en su función de tenante en la heráldica, y las enseñanzas morales que derivan del asalto al Castillo de Amor. Se resalta la similitud con las representaciones del motivo en tabletas de escribir, cofrecillos y espejos de marfil de la época.

Palabras Clave

Hombre salvaje, libros de caballerías, Feliciano de Silva, Florisel de Niquea, Castillo de Amor, Heráldica

\section{Abstract}

This paper focuses on the chapter 77 from the Third part of Feliciano de Silva's Florisel de Niquea. The plot combines a practical joke (recaudo falso) played on the legendary wild man, used as heraldic supporter, with the moral lessons deriving from the Assault on the Castle of Love. It highlights the similarity with the contemporary artistic representations of this motif on ivory writing tablets, caskets and mirrors.

\section{KeYWORDS}

Wild man, Books of Chivalry, Feliciano de Silva, Florisel de Niquea, Castle of Love, Heraldry

Recibido: 01/09/2020

Aceptado: 10/10/2020

1. Este trabajo se inscribe en el marco del Proyecto de Investigación FFI2016-75396-P del Ministerio de Economía y Competitividad, y en las tareas del grupo Clarisel, subvencionado por el Departamento de Ciencia, Tecnología y Universidad del Gobierno de Aragón y por el Fondo Social Europeo. 
El genio burlón de Feliciano le encumbra como maestro indiscutible del humor en los libros de caballerías. Al intuir con su visión renovadora las ventajas del tratamiento jocoso, decidió explotar los indicios dispersos en sus antecesores e introducir con acierto burlas y sales en busca de la amenidad. Creó para ello una serie de personajes que han dejado un recuerdo risueño en la memoria de los aficionados a sus libros. El trío formado por Busendo, Ximiaca y el pastor Darinel pone en solfa los excesos de la perspectiva naturalista del sentimiento erótico con un punto de vista irónico y distanciado sobre la enfermedad de amor y la transformación de los amantes, a la vez que se da sin contemplaciones a esa veta dramática primaria de la risa entremesil, hecha de puñadas, repelones y violencia chusca. Pero es Fraudador de los Ardides quien, sin lugar a dudas, acapara una bien merecida fama al llevar al espacio paradigmático de florestas, encrucijadas de caminos y alrededores de castillos, los falsos recaudos y el arte de motejar propios de las formas de sociabilidad curial. El tema ha sido tratado con acierto en el libro pionero de Cravens (1976) y en la excelente monografía de Daniels (1992). En esta mínima nota, que forma parte de un estudio en curso sobre el tratamiento del hombre salvaje en los libros de caballerías, pretendo exclusivamente llamar la atención sobre un curioso episodio a vueltas con el asalto al Castillo de Amor y con las funciones que el personaje legendario suele desempeñar en el mundo férreamente codificado de la heráldica².

Resumo, antes de nada, las circunstancias de la festiva aventura que tiene sus antecedentes en la batalla de Daraida contra el monstruo Cavalión. En el capítulo 71 de la Tercera parte del Florisel de Niquea, también conocido como Rogel de Grecia I ${ }^{3}$, se cuenta cómo de resultas del extenuante combate, la vencedora, que esconde a Agesilao disfrazado de doncella guerrera, queda convaleciente de sus heridas. Será Galtazira quien reciba el encargo de llevar el cuerpo disecado de la bestia, junto con una carta, a Diana, su madre y princesa de Guindaya. Para el largo viaje harán de escoltas Moncano y Barbarán, caballeros ancianos, según delata la condición parlante de sus nombres $^{4}$, y viejos conocidos del lector. Actúan de alivio de caminantes en esta nueva expedición, con sus excentricidades y conducta desordenada. De hecho, no es la primera vez que sufren las bromas de Fraudador, pues en el capítulo 56 se había encargado de ridiculizar sin ambages la pretensión de rejuvenecer de los dos vejestorios. El caballero burlador les engaña haciéndoles creer que las aguas de una fuente cercana son efectivas a tal propósito:

Pues yendo Barbarán e Moncano con el cavallero de la floresta, a poca pieça que uvieron andado, llegando a un fresco valle el cavallero les dixo:

- Digo's, señores cavalleros, que aquí ayuso está una fuente con una virtud que pienso que no la sabe sino yo e la dueña mi suegra, que a lo menos a ella assaz le ha aprovechado. - ¿Qué virtud es éssa? -dixo Moncano.

\footnotetext{
2. Montaner (1999) dedica unas páginas a la heráldica en los libros de caballerías que ofrecen también excelente fundamentación teórica y un útil repaso diacrónico a la ciencia del blasón. Es modélico el trabajo de Marín Pina (2014-2015) en su aplicación al Mexiano de la Esperanza.

3. Uso la edición de Martín Lalanda (1999) y entre paréntesis indico el número de página, pero tengo en cuenta, al modificar puntuación y mínimos detalles, la de Sevilla, Juan Cromberger, 1546. Véase para los problemas de denominación Eisenberg-Marín (2000).

4. Coduras Bruna (2015).
} 
- Por lo que os precio os diré lo que no pensé dezir a ninguno. Y es que bebiendo d'ella y lavando las barbas y los cabellos torna a los hombres como de la primera edad (167).

En realidad, la falsa Fuente de la Juventud es una treta para robarles los caballos. Dibujados como presuntuosos y machuchos cortesanos que no aprenden la lección, vuelve a engatusarlos bajo parecidas excusas en un segundo encuentro, el del capítulo 77. Me detendré en él porque ahí se desencadena la burla final, objeto de mi atención. El arranque del episodio tiene un inconfundible tono de historia engarzada que recuerda los mecanismos de inserción en las colecciones de cuentos: un grupo de personas recluidas entretienen sus ocios escuchando historias a la vez amenas y edificantes; con una sorprendente novedad en este caso: gracias a la maravilla de una poma mági$c a$, los reunidos en la Torre del Espejo pueden también ver a las damas y caballeros de la aventura. Es el sabio Alquife quien sugiere el tema de la velada:

A gran solaz estavan estos príncipes en la Ínsula no hallada con Alquife e Urganda y, por hazerles plazer, en tanto que Urganda estava rezia para su jornada, cada día el sabio les mostrava en el espejo de la torre muchas aventuras, entre las cuales un día les dixo que, si querían tener paciencia de no dormir una noche, que les mostraría una aventura de que holgassen. Ellos dixeron que no holgarían de cosa más, porque si el sueño los aquexasse, en su mano estava irse a sus lechos. Y con esto, ya que avían comido, él se sube con ellos a la Torre del Espejo y, puestos a su plazer, vieron la presente aventura (237).

La protagonizan los mismos personajes de la anterior, que funciona como antecedente de la nueva treta, ofreciendo, según pasan revista al engaño, materia de reflexión y solaz para entretener la jornada: «Y caminando con mucho plazer, otro día que del puerto salieron, ivan passando tiempo en la burla que Fraudador de los Ardides les avía hecho. Y Barbarán y Moncano dezían que avían quedado avisados para no ser engañados otra vez [...], yendo en esta forma passando muchos donaires» (237-238).

En este segundo encuentro, Fraudador encubre su identidad inventando una excusa caballeresca para no desprenderse del yelmo, lo que permite el nuevo engaño a los incautos. Esta vez les tienta con la presencia de dos damas acompañantes que dicen ser sus hermanas y entablan una conversación de sobreentendidos eróticos con los ancianos. La recuesta de amoríos acaba con la promesa de un encuentro furtivo en el que los pretendientes deberán ser izados por las jóvenes en sendas cuerdas para salvar la guarda del castillo en que se les recluye por las noches. El resultado, aunque previsible, se va preparando entre diálogos ingeniosos de unos y otras.

- Mis buenas señoras, no’s parezca que somos tan viejos como cuidáis, porque en la tierra donde somos todos tienen los cabellos y barvas blancas, que más moços somos de lo que cuidáis.

- Assí me semeja a mí - dixo una d'ellas-, pues las palabras de amor muestran lo que dezís, mas que la naturaleza de vuestra tierra que no me semeja buena.

- ¿Por qué no’s semeja buena? -dixo Barbarán.

- Porque -dixo ella- mejor me pareciera si en la vejez los hombres tornaran moços que en la niñez hazerlos viejos como me semejáis.

- Pues no os lo parezca -dixo Barbarán- que a punto estamos que, si tomáis nuestro consejo, que os desengañaremos d'esse pensamiento.

La donzella se rió e dixo: 
- Si tan seguras estuviéssemos de la bondad del desengaño como de la razón del consejo haríamos lo que pedís, porque vuestra vista pide el consejo e niega el desengaño (238).

La soltura del autor en el manejo de conversaciones plagadas de agudezas y requiebros va dirigiendo la anécdota hacia el clímax de una broma que en la terminología de El cortesano de Castiglione correspondería a un recaudo falso, según traducción de Boscán de lo que es una burla hecha o por obras ${ }^{5}$. La artimaña, que deja a los pretenciosos galanes suspendidos de las almenas y en paños menores, tiene sus antecedentes clásicos: recuérdese a Virgilio, en un episodio del Satyricon de Petronio, expuesto a la vergüenza pública en castigo por su desordenada inclinación hacia las mujeres. La leyenda la recoge, entre otros, el Arcipreste de Hita para ilustrar el pecado de lujuria en su debate con don Amor ${ }^{6}$.

Feliciano hace gala de buen manejo de la cultura aristocrática y, en un momento preciso de la aventura, pone la guinda con una alusión heráldica que no pasaría inadvertida al público familiarizado con la ciencia del blasón. El episodio se prepara minuciosamente en sus detalles: como he dicho, se debe superar el muro de la fortaleza para salvar el encierro de las damas; los aventureros han de ser izados hasta las almenas y, en consecuencia, resuelven ir ligeros, «en calças y jubones». El engaño deja a los dos suspendidos, «hasta más de un estado más alto que la puerta», en perfecta simetría a uno y otro lado del dintel. Porque de esa manera, y según advierten las burladoras («señores cavalleros, atended, que ya os traemos la compañía que os haze menester»), pueden colocar entre ambos el pellejo disecado de la bestia Cavalión. Se compone así un regocijante escudo de armas con dos ridículos tenantes, cuya filiación aclara poco después Fraudador de los Ardides: «Y por lo mucho que amo y estimo a la señora Daraida quiero poner essa bestia, que son sus armas, sobre la puerta d'este castillo, y que las tengan dos tan hermosos salvajes» (240).

La alusión no es gratuita y da cuenta de cómo el estamento nobiliario ha hecho suyos los aspectos positivos de un personaje ambivalente, a medio camino entre el temor que inspira su presencia amenazante, de aspecto feroz, y su asociación totémica con los ritos vinculados a la fertilidad. Los festejos que van del solsticio de invierno al resurgir de la primavera lo erigen en protagonista, por cuanto es figura vinculada al bosque primordial y a las fuerzas de renovación, cifradas en el ciclo de las cosechas y el retorno de la vida ${ }^{7}$. Precisamente por esa función de talismán, la heráldica le reserva a partir del siglo XIV un puesto destacado como soporte de escudos de armas (Fig. 1): conjuga fuerza bruta y augurios de fecundidad para la estirpe ${ }^{8}$. Evidentemente, la broma de Feli-

5. Véase Morreale (1959, vol. I: 218), quien llama la atención sobre el desdoblamiento del término original burle. Pueden verse también: Marín Pina (2002) y Río Nogueras (2004).

6. En las estrofas 261 ss. se encontrará el episodio que fue comentado por Lecoy en 1938. Empleo la reimpresión (1974: 170-171) con material añadido de Alan Deyermond. Véase la nota de la edición de Joset (1981) con bibliografía suplementaria y el recuerdo de otra mención, la del Arcipreste de Talavera en su Corbacho (vol. I: 17). A los antecedentes podrían añadirse, igualmente, las secuelas: el Caballero Metabólico del Cirongilio de Tracia de Bernardo de Vargas, inspirado sin lugar a dudas por Fraudador, deja colgado de una cesta al escudero encargado de negociar el rescate de las caballerías sustraídas a sus amos. Eisenberg recuerda el episodio en relación con la broma, de similares resultados, gastada a don Quijote por Maritornes en el capítulo 43 de la Primera parte. Véanse Río Nogueras (2004) y las matizaciones de Sarmati (2008).

7. Es inexcusable citar los dos trabajos clásicos sobre el personaje: Bernheimer (1952) y Husband (1980). Este último con excelente aparato de imágenes. Pouvreau (2014) trasciende con creces el enfoque iconográfico que confiesa en el título y entra por derecho propio a conformar, junto con los dos citados, la tríada básica sobre el estudio del hombre salvaje. Para el ámbito español se consultan con provecho el repaso pionero de Deyermond (1993), centrado en la novela pastoril, y el muy buen panorama general de López-Ríos (1999)

8. El adelanto a principios del siglo XIV de los datos cronológicos sobre heráldica se hallará en el libro de Pouvreau (2014). 
ciano juega en principio con ese empleo: Barbacán y Montano son los tenantes del escudo; éste luce el trofeo del monstruo abatido como motivo principal del campo. Pero no olvida, en abierta amenaza de Fraudador a los burlados, otras combinaciones posibles: «Y pues tanto amor tenéis a Daraida, justo es que la sirváis por salvages de sus armas, ya que a mí avéis servido, por el amor que tenéis a mis hermanas, de tan gentiles mancebos. Y quedad a la mala ventura si no queréis ser salvajes por cabeças o pellejos de bestias muertas como ess'otra bestia, pues lo pide vuestra edad» (24). El tono fanfarrón de la advertencia les conmina a estar agradecidos por no haber acabado con las cabezas expuestas en algún cuartel, según la costumbre de tantos otros escudos de armas.

No obstante, las implicaciones no se limitan al terreno de la heráldica. Admitamos que la apariencia de Barbacán y Montano poco tiene que ver con la habitual en las representaciones del hombre salvaje, pues nada hay que aluda a lo hirsuto de su presencia o a la asociación con pámpanos y hiedras que suelen coronar su cabeza y ocultar sus vergüenzas. Y habiendo cambiado la inexcusable maza, o tronco sin desbastar, por sus espadas, rasgo disonante en el conjunto ${ }^{9}$, su adscripción a la categoría de hombres salvajes procede más bien de la proverbial rijosidad de sus conductas. El dato, de nuevo, apunta a lo ambivalente: su actuación como raptores y asaltantes violentos viene acompañada en el imaginario de la cultura cortesana de un innegable atractivo erótico. De ahí que se les haga participar, como actores destacados, en festejos donde no faltan lances comprometidos para las damiselas palaciegas ${ }^{10}$. Barbacán y Montano asedian a las jóvenes con su apetito sexual explícito, siguiendo las pautas de comportamiento del personaje legendario, aunque oportunamente disfrazadas aquí con los juegos de palabras y excesos de la religión de amor; atemperados, si acaso, tal y como marca la retórica literaria, con los eufemismos y dobles sentidos del lenguaje poético:

- La orden -dixo una d'ellas- será peligrosa y trabajosa para vós.

- No ay peligro ni trabajo para gozar de tal gloria -dixo Moncano. [...]

- Al infierno por vuestro amor nos atreveríamos a baxar, cuanto más a subir donde están

tales ángeles y gozar de la gloria para salir de la pena que vuestra hermosura nos da (239).

El encuentro, que tiene lugar, precisamente, en el ámbito propio de los asaltos sorpresivos en la floresta, morada por excelencia del personaje, se despliega con una inversión malintencionada, pues, en realidad, son ellos los sorprendidos por la compaña de Fraudador en su jornada de camino. Con pícaras artes de seducción, las hermanas del cuatrero obligan a sus víctimas a desempeñar el papel de comparsas en una desternillante puesta en escena del asedio al Castillo de Amor.

El motivo es de sobras conocido en la literatura y las artes de la época y gozó difusión excepcional en la literatura alegórica, así como en el cancionero cuatrocentista y sus derivados. En las artes decorativas son abundantes las apariciones de la escena, tanto en pequeños cofres de marfil (Figs. 2 y 3 ) como en tablillas para escribir notas sobre cera (Fig. 4) y en más de un peine (Fig. 5) y algún que otro soporte para espejo de mano (Fig. 6), por no hablar de pinturas murales, tapices

9. No obstante, se encuentran excepciones en la representación de sus armas. Así, por ejemplo, en las ilustraciones del manuscrito del Roman d'Alexandre (British Library, Royal Ms. 20 B.xx) blanden espadas y jabalinas. Véase Husband (1980, n. ${ }^{5}$ ). En el folio 15 v $^{\circ}$. del Libro de horas conservado en la Biblioteca Beinecke se puede observar a un hombre salvaje cabalgando un caballo y manejando una espada; en el folio $92 \mathrm{v}^{\circ}$. se presenta con una alabarda y en el folio $24 \mathrm{v}^{\circ}$. carga una ballesta. Véase Cahn y Marrow (1978: 173-284). Pouvreau (2014: 119-127) se ocupa brevemente del contenido. Comento algunos aspectos en Río Nogueras (en prensa).

10. Recuérdense los famosos festejos de Binche en 1559 con ocasión del Felicísimo viaje del príncipe Felipe. Los salvajes irrumpen en el sarao, raptan a las damas y las trasladan a un castillo del que habrán de ser liberadas en la jornada siguiente. Da detallada crónica Calvete de Estrella (2001). Véase Río Nogueras (2012). 
y manuscritos ilustrados ${ }^{11}$. Sus primeros registros coinciden con el siglo XIV y llegan, en lo que ahora nos interesa, a alcanzar la primera mitad del XVI. Probablemente, no es casualidad que esos objetos compartan, junto al motivo central del asedio, figuraciones de Virgilio colgado de la cesta y burlado por una dama (Fig. 7), de Aristóteles cabalgado por Filis (Fig. 8), de la Fuente de la Juventud (Fig. 9). Es la habitual constelación de temas que surge cada vez que se trata del amor y sus peligros. Es obvio que no podían faltar tampoco en los capítulos del Rogel comentados.

Pero quiero detenerme en una curiosa representación del motivo recogida en una vidriera alemana con las armas de la familia Huppe, patricios de la ciudad de Colonia (Fig. 10). Ha sido excelentemente comentada por Husband en su catálogo clásico ${ }^{12}$. Es, en realidad, una trasposición del motivo del asedio amoroso a la iconografía del hombre salvaje. En las escenas que rodean el blasón aparecen tres de estas figuras asaltando el Castillo de Amor. Desde lo alto los reciben unas damas que, por toda defensa, arrojan diademas y pétalos de flores desde las almenas ${ }^{13}$. Los dos asaltantes jóvenes se encaraman a sendas escalas que ocupan los flancos o lóbulos de la vidriera. El salvaje anciano, sin embargo, fracasa en su intento y queda malparado en la base del conjunto, asido con mucho apuro a las mitades rotas de su escalera. La intención satírica se comenta por sí sola y no es muy diferente, en el fondo, a la esgrimida por Feliciano: ridiculizar las pretensiones eróticas de la vejez. Esa alusión final a los salvajes en el culmen de la broma conjuga muy ingeniosamente una función heráldica, propia de la figura legendaria, con su proverbial atracción por las mujeres y sirve para fustigar los intempestivos deseos de Barbarán y Moncano en su asedio fallido al Castillo de Amor. El genio del prolífico escritor acierta al presentarlos en una puesta en escena que resalta los aspectos visuales de la aventura. Compartiendo velada con los personajes recluidos en la Torre del Espejo, junto a Urganda y Alquife, asistimos al bochorno de los burlados, de modo no muy distinto a como las dueñas de esas arquitas, peines y espejos disfrutarían de ellos: admirando la exquisitez del trabajo artístico, pero sin olvidar los castigos morales escondidos entre sus tallas, trazos y perfiles ${ }^{14}$.

\section{Bibliografía}

Bernheimer, Richard (1952), Wild Men in the Middle Ages. A Study in Art, Sentiment and Demonology, Cambridge (Ma), Harvard University Press.

CaHn, Walter y James Marrow (1978), «Medieval and Renaissance Manuscripts at Yale: A Selection», The Yale University Library Gazette, 52 (1978), pp. 173-284 (n. $77,259-261)$.

Calvete de Estrella, Juan Cristóbal (2001), El felicíssimo viaje del muy alto y muy poderoso Príncipe don Phelippe, Madrid, Sociedad Estatal para la conmemoración de los centenarios de Felipe II y Carlos V.

Coduras Bruna, María (2015), Por el nombre se conoce al hombre. Estudios de antroponimia caballeresca, Zaragoza, Prensas de la Universidad de Zaragoza.

11. Desde el temprano artículo de Loomis (1919) y el inventario con minucioso estudio de Koechlin, diversos autores se han ocupado de su estudio y catalogación. Resume bibliografía el trabajo de Pérez González (2016).

12. Husband (1980), n. ${ }^{\circ} 13$.

13. Es ese uno de los aspectos que han servido a la crítica para relacionarlos con celebraciones festivas ligadas tanto a enlaces nupciales como a ritos primaverales. Véase la discusión en Husband (1980) n. ${ }^{\circ} 12$.

14. Roy (2003), en una cuidada argumentación, aboga por interpretar las escenas de estos objetos como un speculum amoris complementario de los tratados morales. 
Cravens, Sydney P. (1976), Feliciano de Silva y los antecedentes de la novela pastoril en sus libros de caballerías, Chapel Hill (N.C.), Estudios de Hispanófila.

Daniels, Marie Cort (1992), The Function of Humor in the Spanish Romances of Chivalry, Nueva York, Garland.

Deyermond, Alan D. (1993), «El hombre salvaje en la ficción sentimental», en Tradiciones y puntos de vista en la ficción sentimental, México, Universidad Nacional Autónoma de México, pp. 17-42.

Eisenberg, Daniel y M.a Carmen Marín Pina (2000), Bibliografía de los libros de caballerías castellanos, Zaragoza, Prensas Universitarias de Zaragoza.

Husband, Timothy (1980), The Wild Man. Medieval Myth and Symbolism, Nueva York, The Metropolitan Museum of Art. [en línea: https://www.metmuseum.org/art/metpublications/ the_wild_man_medieval_myth_and_symbolism].

Juan RuIz, Arcipreste de Hita (1974), Libro de Buen Amor, ed. Jacques Joset, Madrid, EspasaCalpe, 2 vols.

Koechlin, Raymond (1924), Les ivoires gothiques français, París, Auguste Picard, 3 vols.

Lecoy, Félix (1974), Recherches sur le «Libro de Buen Amor» de Juan Ruiz, Archiprêtre de Hita, Farnborough, Gregg International.

Loomis, Roger Sherman (1919), «The allegorical siege in the art of the Middle Ages», The American Journal of Archaelogy, 23, pp. 255-269.

López-Ríos, Santiago (1999), Salvajes y razas monstruosas en la literatura castellana medieval, Madrid, Fundación Universitaria Española.

Marín Pina, M. ${ }^{a}$ Carmen (2002), «El humor en el Clarisel de las flores de Jerónimo de Urrea», en Libros de caballerías (De «Amadís» al «Quijote»). Poética, lectura, representación e identidad, ed. de Eva Belén Carro Carbajal, Laura Puerto Moro y María Sánchez Pérez, Salamanca, Seminario de Estudios Medievales y Renacentistas, Sociedad de Estudios Medievales y Renacentistas, pp. 245-266.

(2014-2015), «La verdad de la mentira: armas de linaje y letras de invención en Mexiano de la Esperanza (1583), un libro de caballerías manuscrito», Emblemata, 20-21, pp. 263-281.

Morreale, Margherita (1959), Castiglione y Boscán: el ideal cortesano en el Renacimiento español, Madrid, Anejos del Boletín de la Real Academia Española, 2 vols.

PÉRez GonzÁlez, Ana (2016), «El Castillo del Amor en las artes figurativas bajomedievales», Revista Digital de Iconografía Medieval, 8, pp. 5-30.

Pouvreau, Florent (2014), Du poil et de la bête. Iconographie du corps sauvage en Occident à la fin du Moyen Âge (XIII ${ }^{e} X V I^{e}$ siècle), París, Comité des Travaux Historiques et Scientifiques.

Río Nogueras, Alberto del (2004), «Libros de caballerías y burlas cortesanas. Sobre algunos episodios del Cirongilio de Tracia y del Clarián de Landanís», en Letteratura cavalleresca tra Italia e Spagna $($ da «Orlando» al «Quijote»). Literatura caballeresca entre España e Italia (del «Orlando» al «Quijote»), dir. Javier Gómez-Montero, Bernhard König, ed. Folke Gernert, Salamanca, Seminario de Estudios Medievales y Renacentistas; Sociedad de Estudios Medievales y Renacentistas, Kiel, CERES de la Universidad de Kiel, pp. 53-65.

(2012), «Motivos folclóricos y espectáculo caballeresco: el príncipe Felipe en las fiestas de Binche en 1549», Revista de poética medieval, 26, 285-302.

(en prensa), «Apuntes sobre el hombre salvaje en los libros de caballerías: Lo crudo y lo cocido en el Felixmarte de Hircania y el Olivante de Laura», en Imaginarios, usos y representaciones en 
los libros de caballerías españoles, ed. M.a del Rosario Aguilar Perdomo y Mario Martín Botero, Bogotá-Antioquía, Universidad Nacional de Colombia-Universidad de Antioquía.

Roy, Bruno (2003), «Archéologie de l'amour courtois. Note sur les miroirs d'ivoire», en Fabienne Pomel (dir.), Miroirs et jeux de miroirs dans la littérature médiévale, Rennes, PUR, pp. 233-251. [en línea: https://books.openedition.org/pur/31896].

SARMATI, Elisabetta (2008), «Maritornes, el caballero Metabólico y Fraudador de los Ardides: una nota al Quijote I, 43 (y a Pedro de Urdemalas II, 554)», en Amadís de Gaula: quinientos años después. Estudios en homenaje a Juan Manuel Cacho Blecua, ed. de José Manuel Lucía Megías y María Carmen Marín Pina, col. Ana Carmen Bueno, Alcalá de Henares, Centro de Estudios Cervantinos, pp. 754-768.

Silva, Feliciano de (1999), Florisel de Niquea (Tercera parte), ed. de Martín Lalanda Javier, Alcalá de Henares, Centro de Estudios Cervantinos.

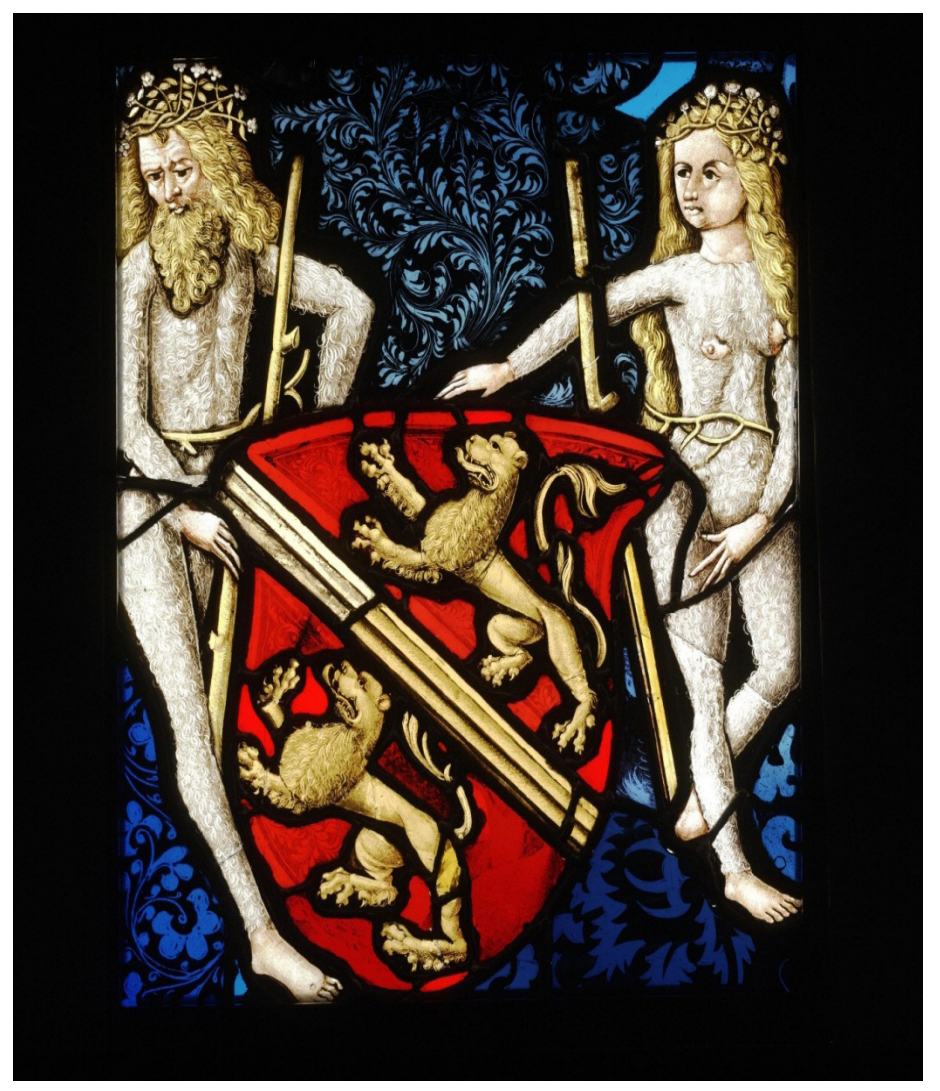

Fig. 1. Vidriera de Lukas Zeiner (c. 1490). Victoria and Albert Museum. Londres 


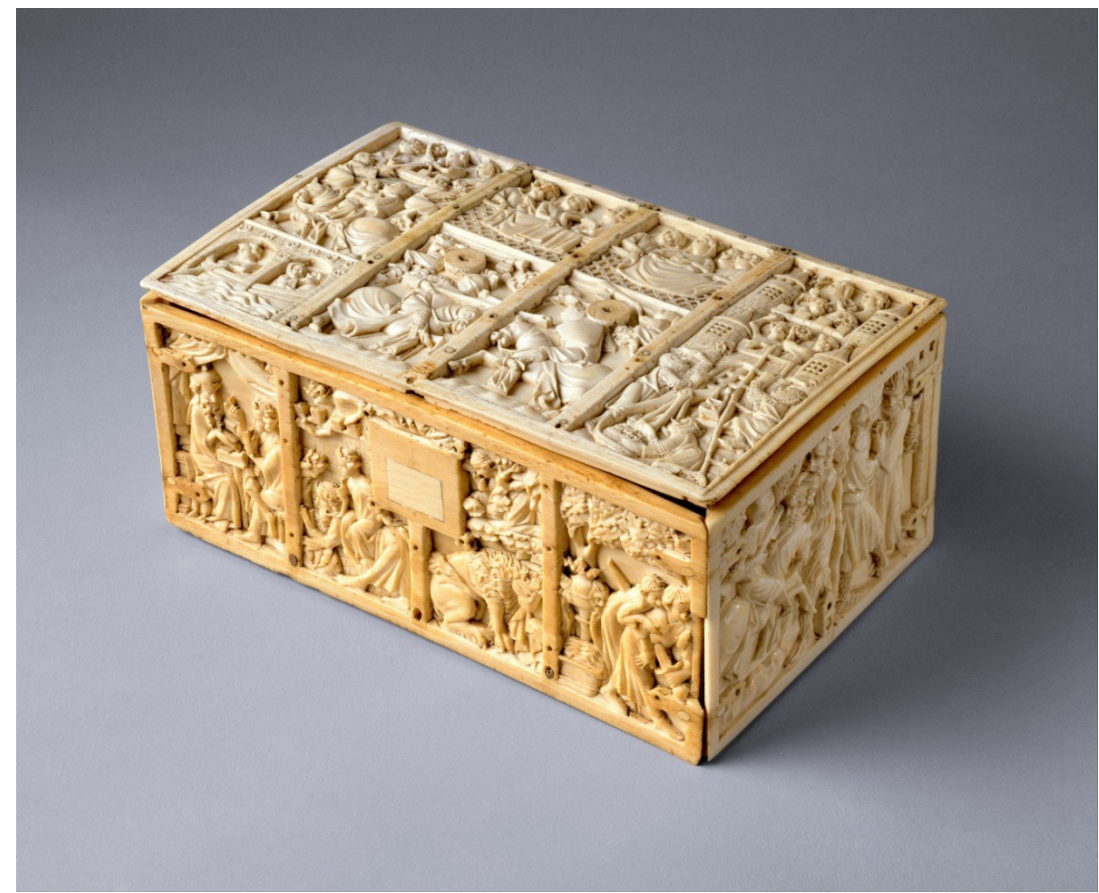

Fig. 2. Cofre de marfil con escenas caballerescas (París, c. 1310-1330). The Met Cloisters. Nueva York

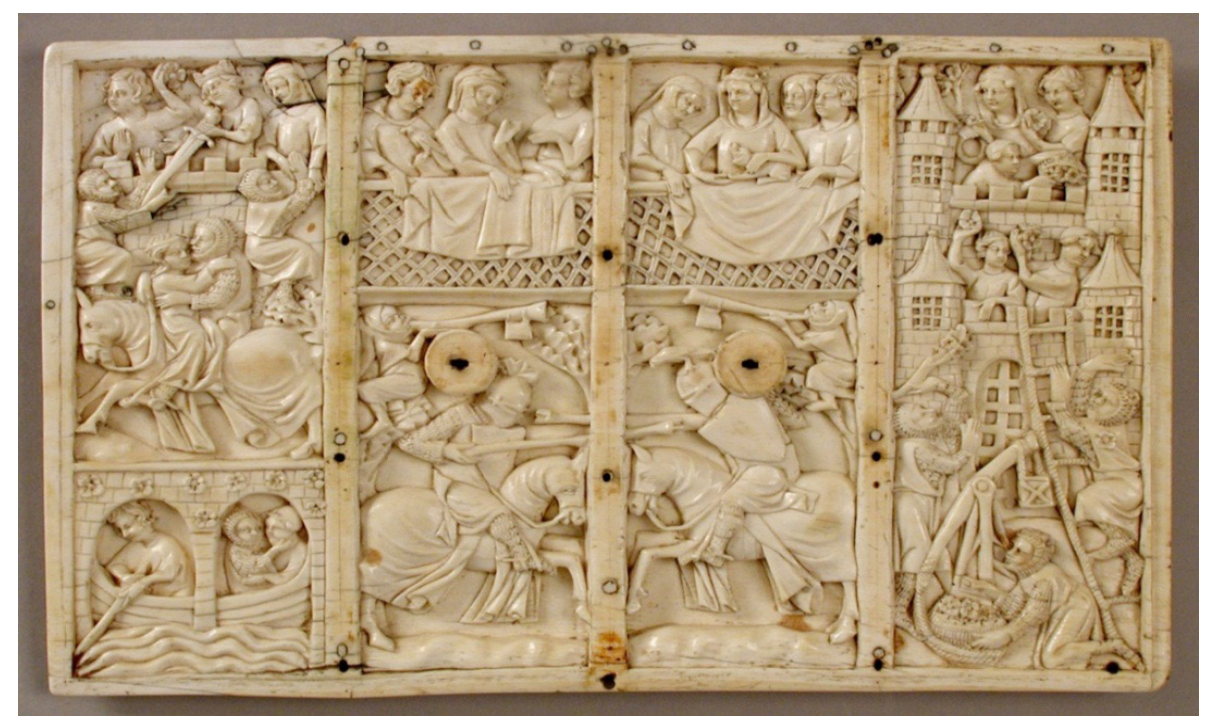

Fig. 3. Panel trasero del cofre de la Fig. 2 con el asalto al Castillo de Amor 


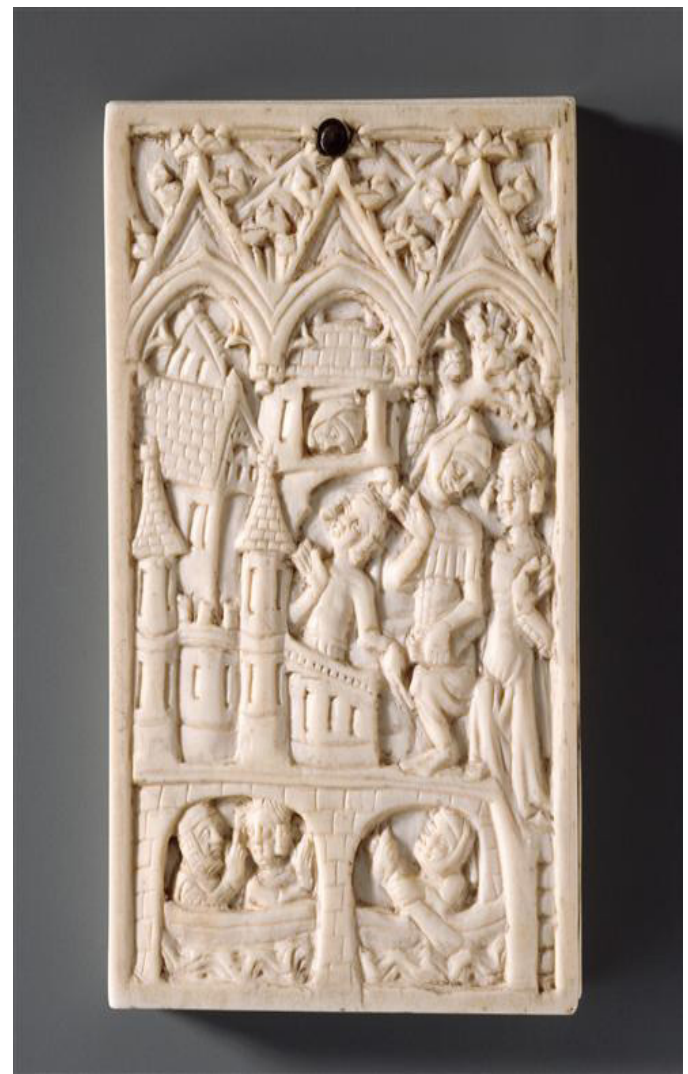

Fig. 4. Tableta de escribir en cera (Vallée de la Meuse, finales del s. XV-principios del XVI). Museo del Louvre. París

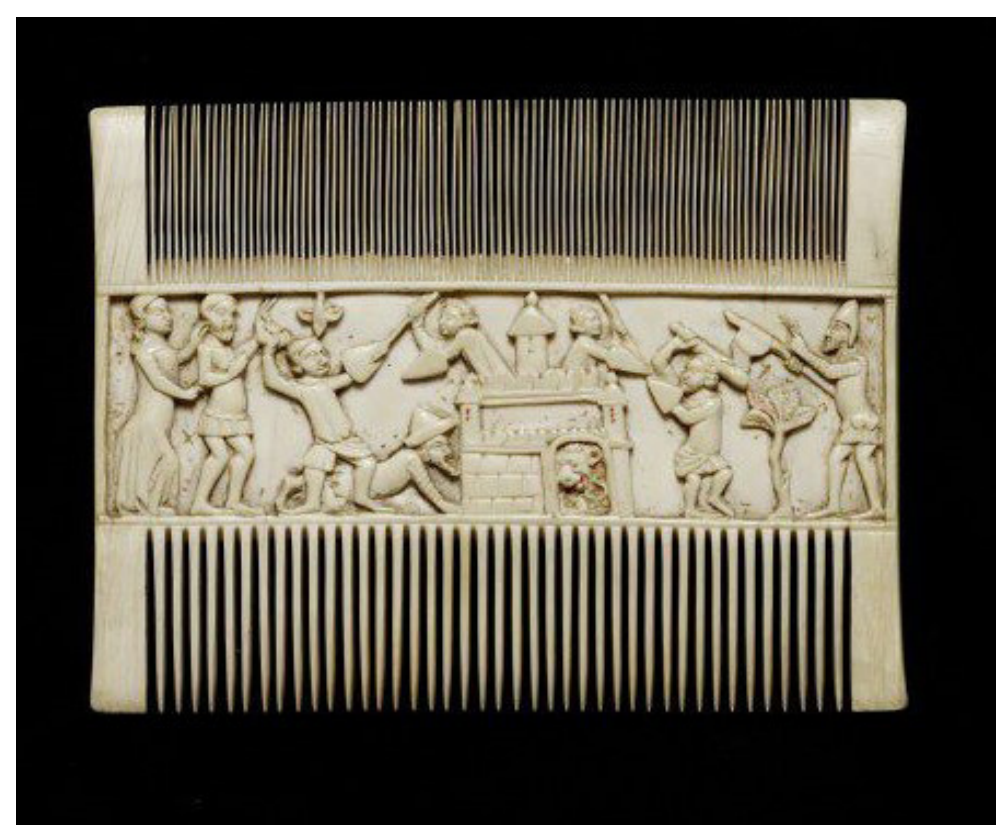

Fig. 5. Peine con escenas del asalto al Castillo de Amor (Venecia, c. 1400). Victoria and Albert Museum. Londres 


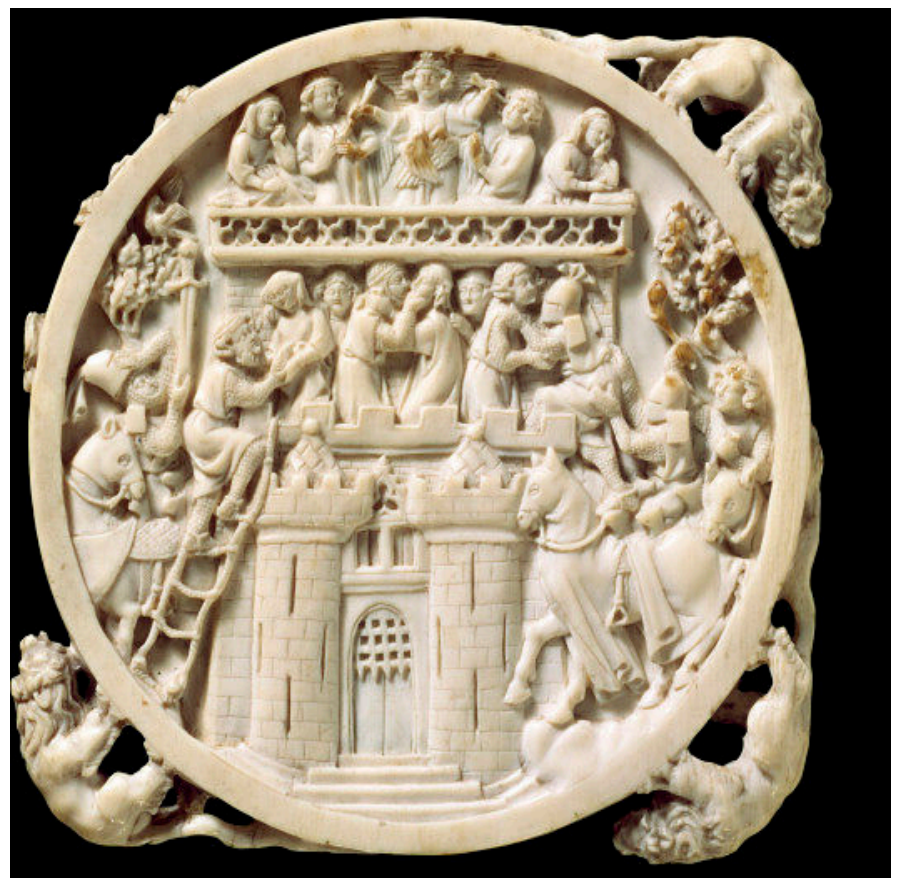

Fig. 6. Soporte de espejo con el asalto al Castillo de Amor (París, c. 1325-1350). Victoria and Albert Museum. Londres

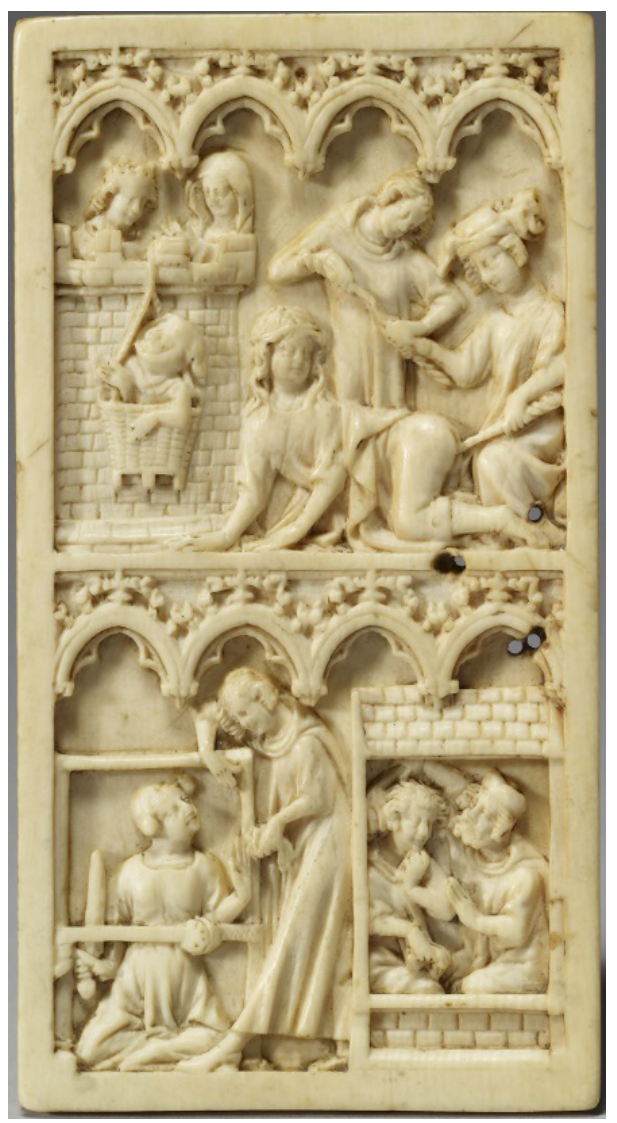

Fig. 7. Tableta de escribir en cera con la burla a Virgilio (Francia, c. 1340-1360). The Walters. Baltimore 


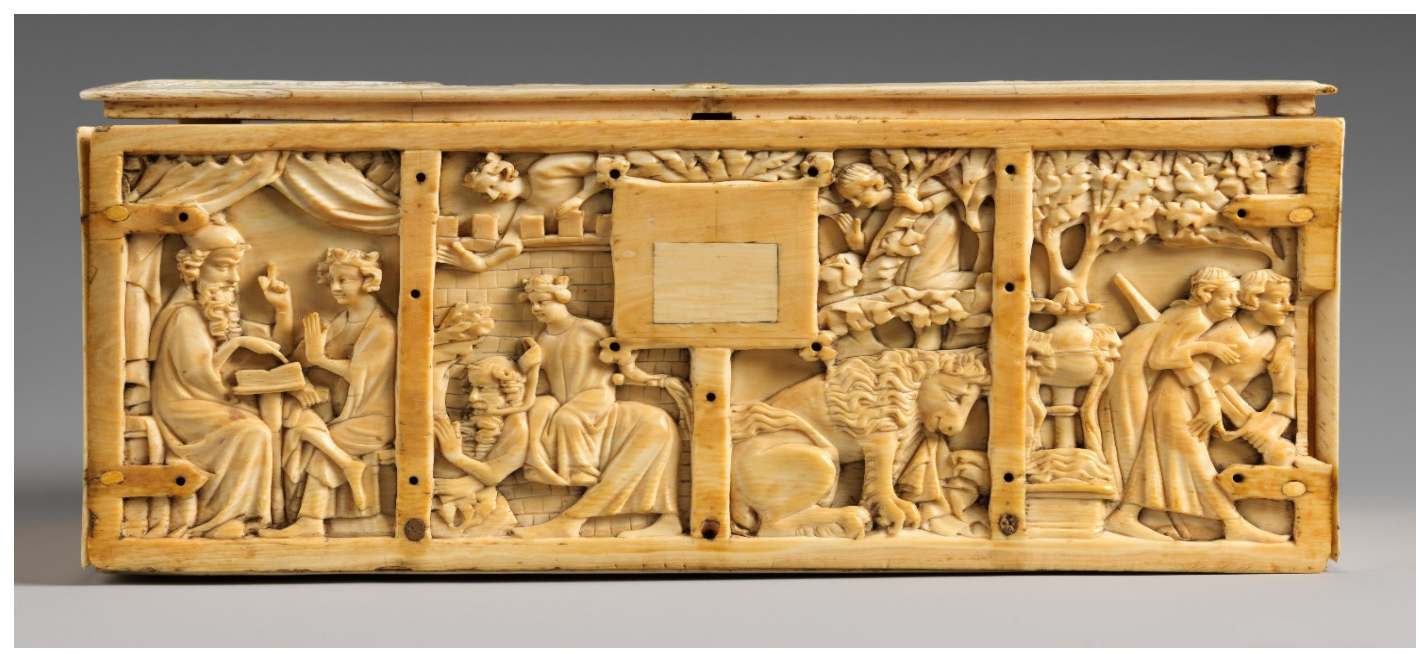

Fig. 8. Panel frontal del cofre de la Fig. 2 con Aristóteles cabalgado por Filis

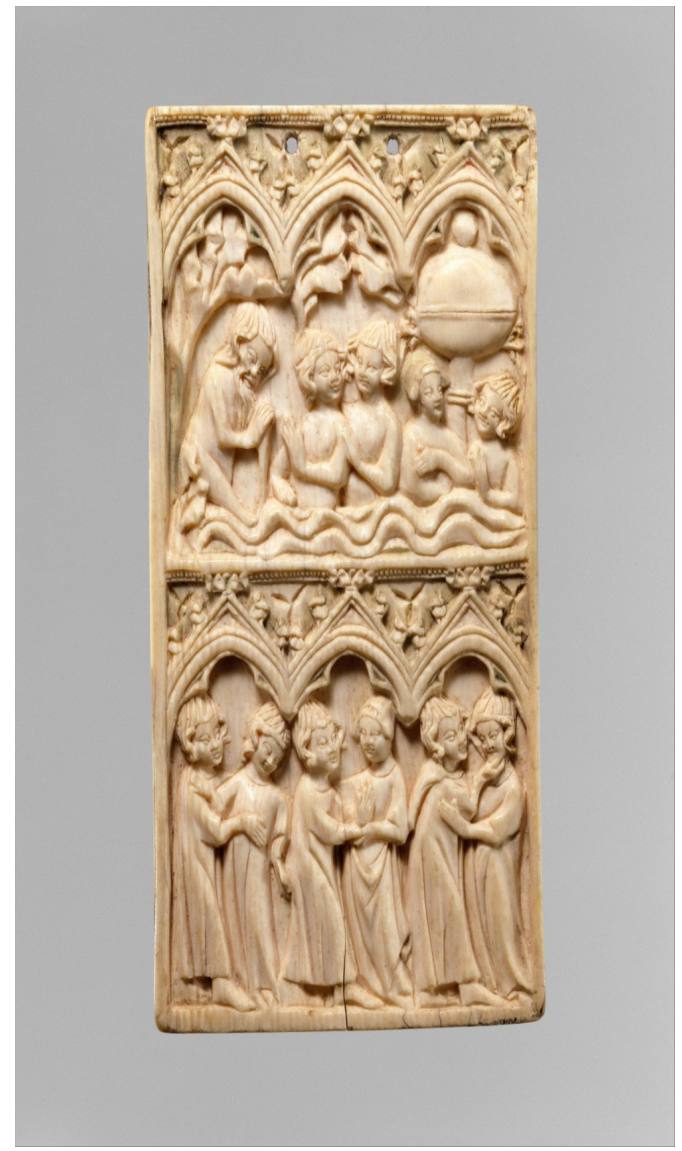

Fig. 9. Tableta de escribir en cera con la Fuente de la Juventud (París, c. 1320-1340). The Met Cloisters. Nueva York 


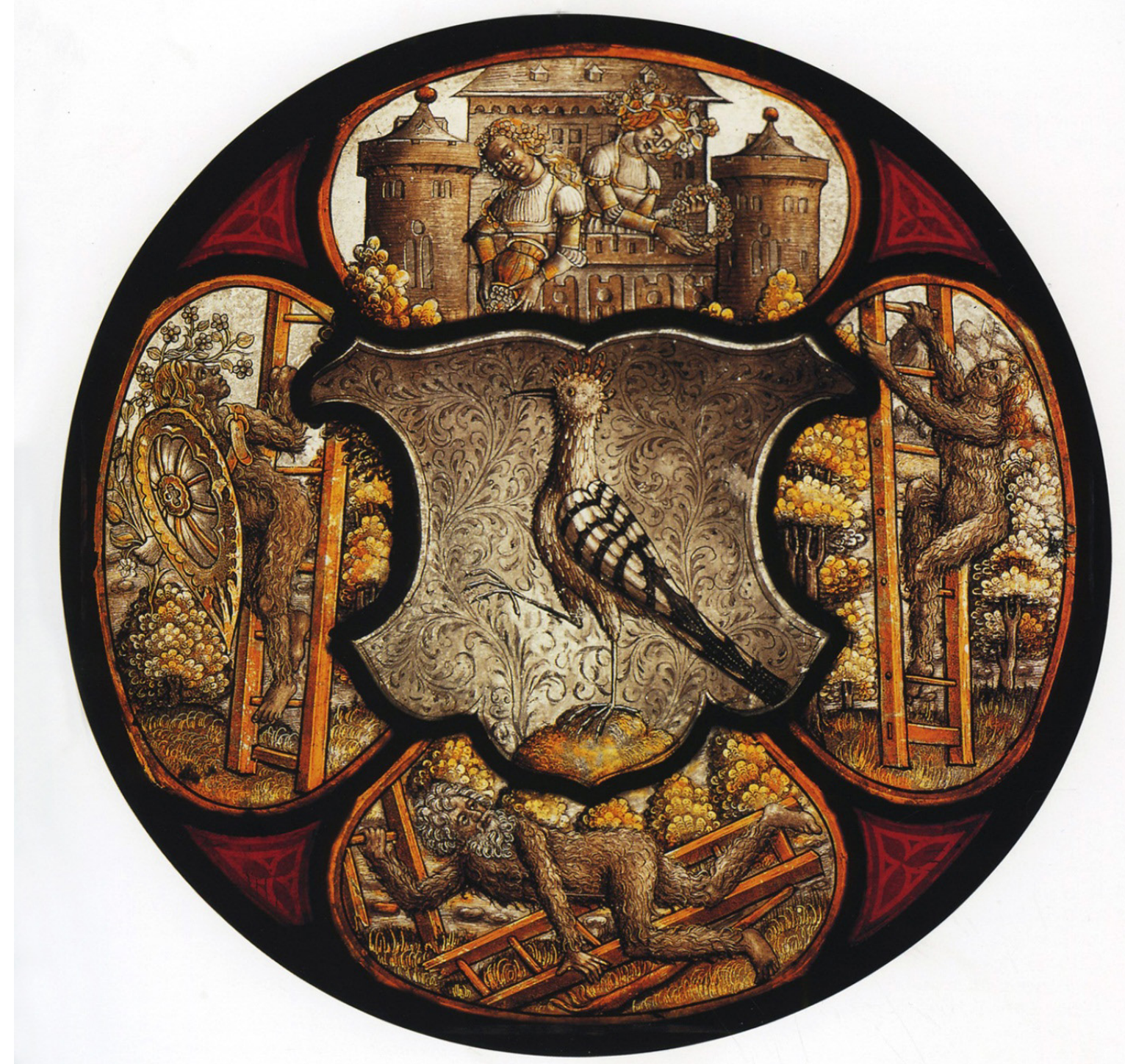

Fig.10. Vidriera con las armas de la familia Huppe (Alemania, c. 1530). Frankfurt. Historisches Museum 
